\title{
Um conceito de ouvinte expandido ${ }^{1}$
}

\section{A concept of expanded listener}

\author{
Nivaldo Ferraz ${ }^{2}$
} conceito de ouvinte expandido. 


\section{Resumo}

Do que pensaram autores da República de Weimar (Bertolt Brecht, Walter Benjamin e Rudolf Arnheim) sobre a relação do rádio com seus ouvintes, passando pela consideração dos estudos culturais ingleses e do conceito de estrutura do sentir de Raymond Williams, pode-se constituir um caminho para a discussão de como o ouvinte experimenta a interatividade com o rádio e com o som nestes dias. A despeito da amplitude atual da participação do ouvinte na programação, ela não chega a contemplar os ideais, principalmente, de Benjamin e Brecht, sendo que, este último, em sua "Teoria do rádio", preconiza um ouvinte que fala na mesma medida do apresentador. $O$ estudo mostra que é possível dimensionar o ouvinte atual como ouvinte expandido, uma extensão ao conceito de rádio expandido de Marcelo Kischinhevsky.

Palavras-chave

Rádio, ouvinte, tecnologia, linguagem, experiência.

\section{Abstract}

From what the authors of the Weimar Republic (Bertolt Brecht, Walter Benjamin and Rudolf Arnheim) thought about the connection between radio and its listeners, going through the consideration of English Cultural Studies and the concept of structure of feeling from Raymond Williams, it is possible to create a path for the discussion of how the listener experiences interactivity with radio and sound nowadays. Despite the current breadth of audience participation in radio programs, this does not contemplate the ideals of Benjamin and Brecht, the latter who, in his Radio Theory, describes a listener that speaks to the same extent as the presenter. The study shows that it is possible to categorize the current listener as an expanded listener, an extension of the expanded radio concept of Marcelo Kischinhevsky.

\section{Keywords}

Radio, listener, technology, language, experience. 


\section{Introdução}

A proposta central deste artigo é apresentar aproximações entre textos e pesquisas a fim de iniciar um processo de estudos que caracterize o conceito de ouvinte expandido. As discussões passarão pela recuperação do que alguns autores falaram e falam sobre a proposta de interação do rádio com o ouvinte desde os princípios da transmissão radiofônica até nossos dias; como também passarão pela evolução da tecnologia, da técnica e da linguagem, três elementos que modificam a forma de abordagem do discurso radiofônico para alcançar o público. Partirei de algumas das primeiras reflexões que se fizeram sobre como o rádio chegava ao ouvinte, produzidas por Walter Benjamin ("Reflections on radio", de 1930 ou 1931), Bertolt Brecht ("Teoria do rádio", de 1927 a 1932) e Rudolf Arnheim ("O diferencial da cegueira", de 1933), para tentar refletir o que diziam sobre o emissor da mensagem radiofônica e o ouvinte.

Considerando a contribuição dos estudos culturais britânicos para os estudos da comunicação, sobretudo o conceito de estrutura do sentir (WILLIAMS, 1980), o artigo faz uma espécie de linha do tempo não-formal da relação entre o ouvinte e o rádio brasileiro, entra na atualidade, discute a virtualidade como não-território e o podcast como a resposta do rádio à modificação imposta pelas vias digitais, para chegar ao conceito de ouvinte expandido, em extensão ao conceito de rádio expandido estabelecido por Marcelo Kischinhevsky $(2016)^{3}$.

\section{Do pensamento alemão sobre o rádio aos Estudos Culturais britânicos}

O filósofo alemão Walter Benjamin trabalhou no rádio do país no entreguerras, quando a difícil situação econômica o levou a buscar alternativas de sobrevivência. Durante este período escreveu alguns ensaios sobre o rádio, além de muitos roteiros de programas educativos para crianças. Um dos artigos que escreveu é "Reflections on radio", de 1930 ou 1931, no qual sustenta que o rádio tem interesse em trazer 
a conhecimento público a voz das pessoas que tenham algo a dizer. Esta é sim uma ideia compartilhada com seu amigo, o teatrólogo Bertolt Brecht, colega de crítica das artes, da comunicação e de ideologia, com quem trabalhou com a linguagem no rádio da Alemanha nos anos 1930. A coincidência de pensamento entre os dois a respeito do rádio e do controle de uma informação que, para eles, em sua luta ideológica trazia a barbárie, é refletida na "Teoria do rádio" de Brecht, na qual o teatrólogo criticava a não existência de uma via de participação do público ouvinte e alertava os diretores de programação das emissoras que o

rádio seria o mais fabuloso meio de comunicação imaginável na vida pública, um fantástico sistema de canalização. Isto é, seria se não somente fosse capaz de emitir, como também de receber; portanto, se conseguisse não apenas se fazer escutar pelo ouvinte, mas também pôr-se em comunicação com ele. A radiodifusão deveria, consequentemente, afastarse dos que a abastecem e constituir os radiouvintes como abastecedores. (BRECHT, 2005, p. 42)

De forma clara, ambos estavam a favor da participação popular, aberta e em igualdade de condições com os controladores de conteúdo das rádios alemãs. Tornar o ouvinte especialista fatalmente passava pela experiência que Walter Benjamin reivindicava em favor do ouvinte na relação com o rádio. A questão da experiência é preocupação latente nos escritos de Benjamin e ele a transferiu também para sua reflexão sobre o rádio. A crítica de Benjamin e Brecht à não participação do público ouvinte no rádio encontrava muitos pontos de convergência em favor de uma política e de um estado democráticos, assim como era uma crítica direta ao centralismo de poder do governo. Benjamin e Brecht lutavam com sua arte, pensamento e crítica para tirar o rádio do controle burguês, que oferecia uma sofisticada programação de substituição "do teatro, da ópera, do concerto, da imprensa local etc. Desde o princípio a radiodifusão imitou todas as instituições existentes que tinham algo a ver com a difusão da palavra ou do canto" (BRECHT, 2005, p. 32). A questão que paira nos pensamentos de Benjamin e, principalmente, de Brecht, é de que essas transmissões iniciais, em sua origem, traziam na forma da arte a necessidade de se visualizar o que ocorria em cena, de modo que a questão visual para um público 
burguês estava estabelecida e, na transmissão pelo rádio, a ausência de imagem causava estranheza a esse público. Rudolf Arnheim expressou, na mesma época, um pensamento semelhante, ao comentar sobre as características sonoras do rádio e sua incompatibilidade com o visual nas transmissões de peças e óperas desde os teatros sem adaptação à linguagem radiofônica, de forma que o ouvinte perceberia "pessoas andando de lá para cá sem saber o que estão fazendo, ouve aplausos e exclamações sem captar o que se passou em cena" (ARNHEIM, 2005, p. 64). A percepção dos três pensadores era de que a recepção da transmissão de um som com a necessidade de complementação visual no imaginário do ouvinte - típica de uma visão burguesa sobre o rádio - não funcionaria, afinal, porque ao rádio "nada Ihe falta! Pois a essência do rádio consiste justamente em oferecer a totalidade somente por meio sonoro." (ARNHEIM, 2005, p. 62). Com a mesma fixação que teve Arnheim sobre o desastre que seria o costume burguês do culto à imagem para o rádio, Benjamin fala de uma época e um lugar onde

\footnotetext{
com o fomento implacável de uma mentalidade consumista entre frequentadores de ópera, leitores de novela, turistas, e mais, criam-se massas apagadas e desarticuladas - uma audiência no sentido estrito da palavra, sem critérios para seus julgamentos, nem linguagem para seus sentimentos. (BENJAMIN, 2014b, p. 363, tradução nossa)
}

De alguma forma, os três contemporâneos eram contaminados pela experiência operária com a feitura de aparelhos de rádio, ao final dos anos 1910. "Esse tipo de entretenimento não somente permitia ao trabalhador exercer uma atividade criativa [...] para as horas de lazer [...] como the possibilitava [...] ampliar consideravelmente seu interesse pelos assuntos da vida coletiva" (MARCONDES FILHO, 1982, p. 29). Também estavam impactados pela participação do rádio na revolta dos marinheiros em Kiel (1918), sendo esse um dos fatos políticos que iniciaram a República de Weimar ${ }^{4}$. Observavam certamente as diferenças entre um rádio que funcionou pela insurreição de trabalhadores explorados, comparado a um rádio de posse de empresas 
que preferiam disseminar costumes burgueses. Onde ficava, então, o ouvinte e seu consumo cultural das informações entre estes dois universos radiofônicos? Este era o fundamento das críticas.

Assim como os operários de Weimar se inseriram em uma nova vida cotidiana pela experiência da produção de seus aparelhos de rádio, para Benjamin, a experiência narrada entre gerações - constituinte da expressão radiofônica, uma vez que falada - é fundamental para, olhando o passado, estabelecer-se um novo presente com vistas a um melhor futuro. A questão da experiência está cravada, por exemplo, em "Experiência e pobreza", em que

está claro que as ações da experiência estão em baixa, e isso numa geração que entre 1914 e 1918 viveu uma das mais terríveis experiências da história universal. [...] Na época, já se podia notar que os combatentes voltavam silenciosos do campo de batalha. (BENJAMIN, 2014a, p. 124)

Benjamin se referia aos combatentes vivos da Primeira Guerra, cujo trauma da experiência passada nas trincheiras calava-os naquele presente. Deixando de narrar a experiência, o homem não voltava a tomar posse de sua territorialidade original.

A reivindicação de Benjamin por um novo presente a sanear a torpeza dos sobreviventes da Primeira Guerra é uma das sementes fundadoras do que anos mais tarde (década de 1950), pelos estudos culturais britânicos, iríamos conhecer como estrutura do sentir de Raymond Williams, um braço de conexão entre estudos culturais e Escola de Frankfurt, pelo caminho da experiência como conceito em Benjamin, ao considerar a experiência que traz ao homem comum o sentir no momento (a falta de narração, no caso dos soldados alemães). Um sentimento novo e só transitório dependendo da solução que os narradores silenciados dessem para suas narrativas no presente e no futuro.

Esse sentir como expressão de uma nova experiência é um estado recorrente na interatividade entre o ouvinte e o rádio nos dias de hoje. Uma vez que, em Williams, o social, que seria o fixo, o explícito, o conhecido, já está dado, o que valerá na experiência do público com o rádio e como fundamento da estrutura do sentir é "tudo o que é presente, mobilizador, tudo o que escapa ou parece escapar 
do fixo, do explícito e o conhecido é compreendido e definido como o pessoal: isto, aqui, agora, vivo, ativo, 'subjetivo'"' (WILLIAMS, 1980, p. 151, tradução nossa). Apesar de o conceito ter sido desenvolvido nos anos 1950 e diante de um sistema de meios de comunicação de massa, ele continua aplicável nos dias de hoje ao pensarmos a relação do ouvinte com a sonoridade original do rádio com a qual ele lida na contemporânea vida digital. Afinal, as oportunidades de interatividade se alastram a oferecer oportunidades de um momento não registrado socialmente e que é no "agora" e "ativo", duas das expressões de Williams que une o conceito à ação do internauta. Um dos teóricos fundamentais dos estudos culturais ingleses, Stuart Hall, percorre um caminho de explicações para chegar à estrutura do sentir, retirando o formato emocional das expressões de Williams para definir o fenômeno e devolvendo-o como um resultado de estudo social apurado. Para Hall (2013), Williams chegou ao conceito quando constituía uma forma viável de analisar a cultura segundo uma natureza de organização que forma o complexo de todos os relacionamentos. Segundo Hall, a "cultura não é uma prática; nem apenas a soma descritiva dos costumes e 'culturas populares [folkways]', a cultura é esse padrão de organização, essas formas características de energia humana que podem ser descobertas como reveladoras em si mesmas" (HALL, 2013, p. 149). E o "propósito da análise [dos padrões de organização] é entender como inter-relações de todas essas práticas e padrões são vividas e experimentadas como um todo, em um dado período: essa é sua 'estrutura de experiência'"' (HALL, 2013, p. 149). Aqui se vê uma aproximação entre Williams e Benjamin pela palavra experiência, pois o original structure of feeling, que tenho traduzido como estrutura do sentir, ganha na tradução da Editora da UFMG a expressão estrutura de experiência, com aval de conhecedores dos estudos culturais como Adelaine LaGuardia-Resende, Ana Carolina Escosteguy, Cláudia Álvares, Francisco Rüdiger e Sayonara Amaral. Não é apenas o conceito da experiência em Benjamin e a estrutura do sentir (ou de experiência) em Williams o que une os dois teóricos. O próprio britânico, na introdução de sua obra Marxismo e literatura, relaciona Benjamin entre um dos autores marxistas a quem ele dedicava especial atenção (WILLIAMS, 1980, p. 15). 


\section{Alguns conceitos de massa}

Em seu livro Television (publicado em 1974), Williams, quando observou os modos de consumo do público por informações da televisão britânica, entendeu que

\footnotetext{
"Massas" foi um termo oitocentista (século XIX) de desprezo para o que era anteriormente chamado de "turba". A "massa" física da revolução urbana e industrial ajudou a consolidar a expressão. [...] a palavra "massa" passa então a significar grandes números [...] O rádio e a televisão [...] foram desenvolvidos para transmissão em casas individuais [...] Assim, essa nova forma de comunicação social - radiodifusão - foi obscurecida em sua definição como "comunicação de massa". (WILLIAMS, 2016, p. 36)
}

Pela desqualificação do termo "massa" como conceito de público e, ao mesmo tempo, a qualificação do rádio e da televisão como meios difundidos em casas individuais, os estudos culturais fundam um participante - no nosso caso o ouvinte - que é não massificado, que é individualizado por sua experiência, pela estrutura do sentir na individual vivência do presente, desestruturando o conceito de massa a ele atribuído por conta do que ele de fato significa, um ser social único. Por outro lado, as determinações de "massa" e "grande público" continuaram a pertencer a muitos estudos, inclusive culturais com seus vários ramos, até pelo menos os anos 1990, quando ainda se expressava um público com identidade de massa e não indivíduo a indivíduo. Para Dominique Wolton, o grande público é sempre identificado como sociedade de massa. Identificação que origina o nascimento da opinião pública, em que "o grande público é o público das mídias de massa, à frente das quais se encontram o rádio, depois o cinema, e por último a televisão" (WOLTON, 1996, p. 125). Pela época destes estudos e diante da certeza de Wolton, é possível compreender a visão a respeito de "grande público" representativo da "massa" e de como ele consome mensagens vinculadas às massas dos meios de comunicação do século $\mathrm{XX}$, sem poder considerar a futura devastação destes conceitos que praticam a cultura de convergência, de conexão e de transmidialidade expostas por Henry Jenkins (2006 a 2014). Tampouco previra o encaminhamento a outro lugar para os meios de comunicação de massa. 
Este novo padrão de relacionamento a gosto dos estudos culturais e que expande o conceito do rádio tradicional provoca ações de interação no ouvinte que o torna ouvinte expandido. O estudo de um padrão de produção desta energia humana na interação com o rádio expandido e que, ao liberar a energia da estrutura do sentir, caracterizará o ouvinte expandido.

\section{O rádio e a mudança narrativa que mostra resiliência}

Demonstrando a partir de vários autores que discutem, sem anunciar, a morte de cada meio massivo, Mário Carlón e Carlos Scolari (2014) organizam um livro que mostra o ressuscitar desses meios na lida com a vida digital, tendo o rádio - com melhores estratégias de envolvimento com a internet e com softwares afeitos ao som e, aparentemente, por ter adquirido marcas de lutas anteriores em reação à ocupação de espaço pela televisão - se saído melhor na lida com meios digitais do que outros como o livro, a imprensa, o cinema e a própria televisão. Explicam os organizadores que "As notícias que nos chegam do front radiofônico são positivas: o rádio, este bom objeto tão amado por gerações, de enganosa debilidade, parece ter sido sempre na história um dos meios melhor preparados para resistir" (CARLÓN; SCOLARI, 2014, p. 8, tradução nossa) 5 . Esta é uma das várias provas que sustentam ser um erro brutal secundarizar a importância do rádio como instituição social nos dias de hoje. Além disso, pelo fácil envolvimento do rádio com as redes sociais e as formas digitais de produção, transmissão e espalhamento, a audição dos sons de origem radiofônica vai se multiplicando e diversificando o consumo cultural do ouvinte. A sobrevivência do rádio é possível pela resiliência de um ouvinte que vai expandindo sua participação na medida em que surgem ferramentas para isso.

O ouvinte tradicional pelas ondas hertzianas, que lidava e ainda lida com o rádio da maneira formal de consumo, teve facilitado o acesso à tecnologia 
radiofônica, por seu rápido barateamento. Esta acessibilidade está ligada aos processos de industrialização e urbanização ocorridos no Brasil no início do século XX. Com o acesso das populações das maiores cidades brasileiras ao rádio, formaramse grandes públicos de classes populares, o que forçou as emissoras a produzir conteúdo de linguagem mais popular, tanto na fala quanto na música a ser apresentada. O rádio lançou modas - de comportamento, éticas e morais com claro fundo religioso, em que as famílias que o consomem devem ser todas formadas por marido, mulher, filhos e animais de estimação, chegando uma parte das famílias que ouviram rádio coletivamente - a discutir questões da comunidade sob a característica do rádio local, que articula denúncia e pressão para as autoridades tomarem providência. Falo sobre o ouvinte metropolitano principalmente, de cidades grandes e médias do Brasil. Não falo dos ouvintes das regiões rurais brasileiras, esses ainda mais abandonados com as últimas ações de migração de emissoras de AM para FM, que diminui o leque de escolhas no dial desse ouvinte rural, diminuindo opções de lazer, entretenimento e informação. São ouvintes que perdem a chance de serem expandidos.

Como ao Brasil não interessou investir em uma estrutura de rede nacional forte e efetiva, como a NPR nos Estados Unidos ou BBC na Grã-Bretanha, a única solução para encontrar algum discurso que tenha feito o ouvinte de rádio convencional participar foi e será sempre o rádio local, aquele que alcança poucas cidades pequenas coligadas, algumas cidades médias, ou ainda grandes cidades apenas como seu universo.

O rádio comercial e a popularização do veículo implicaram a criação de um elo entre o indivíduo e a coletividade, mostrando-se capaz não apenas de vender produtos e ditar "modas", como também de mobilizar massas, levando-as a uma participação ativa na vida nacional. Os progressos da industrialização ampliavam o mercado consumidor, criando condições para padronização de gostos, crenças e valores. As classes médias urbanas (principal público ouvinte do rádio) passariam a se considerar parte integrante do universo simbólico representado pela nação. Pelo rádio, o indivíduo encontra a nação, de forma idílica: não a nação ela própria, mas a imagem dela que está se formando. (MIRANDA, s.d. apud ORTRIWANO, 1985, p. 19) 
Além dessa situação acima, duas novas ordens, uma tecnológica, outra em consequência desta, desencadearam também uma aproximação do comunicador com sua audiência, seu público em potencial, podendo tornar o ouvinte mais participativo emocionalmente: a invenção e aplicação do transistor (anos 1950 e 1960) à tecnologia do rádio, tornando-o portátil, grudado ao corpo do ouvinte, "de sorte que o transistor tornou-se o apêndice corporal, a prótese auditiva, o novo órgão de ficção científica" (BARTHES, 2008, p. 214) e obrigou que houvesse uma mudança na linguagem do comunicador. Com um aparelho com portabilidade, individual e personalizado, pela primeira vez na história mundial das comunicações, o ouvinte necessitou de um discurso radiofônico que mudava o tratamento em relação a ele da segunda pessoa do plural (vocês, na apresentação do comunicador para um grupo de ouvintes em torno do rádio) para a segunda pessoa do singular (você, direcionado a uma única pessoa com o radinho de pilha colado ao ouvido), sendo, portanto, uma estratégia mercadológica a questão de popularização da linguagem que apresentadores utilizam no rádio.

Facilitou-se a participação do ouvinte nas programações através de cartas e telefonemas desde meados dos anos 1940 e, contemporaneamente, por meio de mensagens em várias plataformas on-line, gravação de voz dos ouvintes via softwares e emissões por vias digitais. Telefonemas e mensagens por WhatsApp puderam entrar diretamente na audição, com o ouvinte ganhando vez com sua própria voz no ar, falando por si mesmo no rádio. A experiência compartilhada nas redes sociais, nos tempos de hoje, promove a criação virtual de comunidades em que a troca de experiência pela comunicação oral de tempos atrás passa a ser a troca de experiência em comunicação digital, escrita, imagética e sonora, repondo, na contemporaneidade, o homem não de gerações passadas, mas um homem de gerações somadas, que se reorganiza em torno das muitas informações que recebe e compartilha, vivenciando a experiência do sentir. Um homem que se dá o poder de sentir-se comunitário, com pertencimento a seus grupos de interesse comum, a restabelecer o conceito de comunidade de ouvintes, que seriam 
grupos que se constituem ao redor de um mesmo processo de enunciação e aí estabelecem uma conexão por reconhecimento. Os múltiplos contratos que se estabelecem revelam a busca, pelo ouvinte, de mensagens que o levam a experiências diversas - que o façam sentir-se integrado ao mundo, mas que também se traduzem em um start no imaginário de cada um. (SALOMÃO, 2003, p. 26)

Essa comunidade de ouvintes se corporifica à medida em que o ouvinte encontra condições de estabelecer contato com a emissora pelas vias oferecidas e, a partir disso, constitui a "comunidade" em seu imaginário, por identificação com outros ouvintes que podem participar também. Os elos entre apresentador e ouvinte viabilizam

a convivência mediatizada de um cotidiano que resulta de um mundo agora extremamente complexificado. E é nesta contemporaneidade muitas vezes incompreensível e perversa aos olhos do cidadão comum que o rádio, com sua maneira própria de perceber e contar as coisas da vida, parece surgir como uma ilha onde o ouvinte sente-se mais seguro. Seja pela oferta de uma farta coloquialidade, de uma generosa previsibilidade para a construção do discurso, ou pela garantia permanente de companhia e de possibilidade de pertenciamento a uma "família" de ouvintes, o rádio seduz, por privilegiar essa comunicação, de caráter acima de tudo relacional. (SALOMÃO, 2003, p. 26)

É necessário lembrar que essa participação ainda conta com o controle do emissor no sistema de rádio broadcasting, em que apresentadores, quando não a produção de programas e faixas de programação, controlam o que vai ao ar vindo dos ouvintes. Isso não torna a experiência do ouvinte atual igual à desejada por Benjamin, na esteira de Brecht, como alguém que participa ativamente da programação, falando quantitativamente na mesma medida em que escuta, ainda que

Cada vez mais vivemos em um mundo muito mais mutável, onde cada um tem necessidade de se sentir em comunidade como há centenas de anos. Ora, não vivemos mais na vila onde nascemos. Essas tecnologias permitem recriar de maneira virtual essa necessidade. (BURGELMAN, 2006, apud MIÈGE, 2009, p. 85) 
Muito de nossa vida social modificou-se nas últimas décadas, depois que passamos a lidar com qualquer modelo digital que

não é lido ou interpretado como um texto clássico, ele geralmente é explorado de forma interativa. Contrariamente à maioria das descrições funcionais sobre papel ou aos modelos reduzidos analógicos, o modelo informático é essencialmente plástico, dinâmico, dotado de uma certa autonomia de ação e reação. (LÉVY, 1993, p. 121)

Enquanto Pierre Lévy avança na exploração de como nosso pensamento se modifica com a experiência virtual, o ouvinte de um conteúdo em áudio já experimenta isso, pois possui a possibilidade de deixar o comportamento da audição radiofônica ao vivo, sendo que, para ele, "o conhecimento por simulação e a interconexão em tempo real valorizam o momento oportuno, a situação, as circunstâncias relativas por oposição ao sentido molar da história ou à verdade fora do tempo e do espaço, que talvez fossem apenas efeitos da escrita." (LÉVY, 1993, p. 126). A despeito de certa desqualificação exagerada da escrita, que é secular nos processos de construção das culturas, a questão das relações de tempo e espaço virtual com o tempo e espaço real é muito cara à cultura digital. Neste novo universo, o tempo é intemporal e os espaços se dão por fluxos, que "são as bases principais de uma nova cultura, que transcende e inclui a diversidade dos sistemas de representação historicamente transmitidos" (CASTELLS, 2006, p. 462). $\mathrm{Na}$ relação do rádio com a internet se fundam web emissoras com evidente transgressão do tempo e do espaço reais, sejam web rádios ou rádios hertzianas que proponham diversidade digital na comunicação por seus sites.

Se superam as divisões tradicionais de rádio local, regional, [...] nacional, internacional. [...] É preciso superar a concepção de ciberespaço já que neste caso entra em funcionamento não só o espaço, como também o tempo e a combinação de ambos. ${ }^{6}$ (HERREROS, 2008, p. 27, tradução nossa) 
Essa transgressão de tempo e espaço torna o universo do rádio na internet um campo muito distinto do rádio tradicional, em que os elementos comuns das vias digitais, como hipertexto em convergência de som, imagem estática e em movimento, criam um lugar que continua sendo rádio, um rádio renascido na possibilidade de tornar o ouvinte/internauta mais ativo e falante, embora não como na radical proposta de Benjamin e Brecht, mas um rádio possível e, por último, o rádio expandido de Kischinhevsky, "que extrapola as transmissões em ondas hertzianas e transborda para mídias sociais, o celular, a TV por assinatura, sites de jornais, portais de música" (KISCHINHEVSKY, 2016, p. 13). Assim, o pesquisador caracteriza o conceito de rádio expandido.

Por este caminho de avaliar a evolução da participação na medida em que o rádio se expande desde os anos 1930, na Alemanha de Benjamin, Brecht e Arnheim, aos dias de hoje, já pode-se pensar em dar o salto para um ouvinte, ele também expandido. Mas vou seguir um rápido caminho histórico do ouvinte de rádio e sua interação não apenas com o veículo, mas com um produto contemporâneo com características radiofônicas, do qual trato a seguir.

\section{Sob a pressão do mundo digital, a resposta do rádio é o podcasting como narrativa}

Um modelo de negócio que ainda se articula sem maturidade na propagação do universo digital brasileiro, mas que prospera imensamente em continentes como Europa e países como Estados Unidos, é a novidade do rádio para uma sociedade em rede: o podcasting como processo e o podcast como produto. A possibilidade de acesso tecnológico a um eficiente e não custoso parque técnico que resolve todas as questões não é somente entregar em alta resolução sonora a produção feita, mas dar a possibilidade de inúmeras expressões, falas, discursos, assuntos, formas políticas, econômicas e de luta de classes distintas poderem surgir. Não há um controle central para decidir o que vai ser pautado como a verdade a ser descoberta, princípio do jornalismo. Livre de um poder central, o usuário pode buscar até encontrar um assunto ou, mais interessante a um estudo de linguagem, buscar uma narrativa 
diferente para um fato comum que atinge a alma humana. O podcast, podendo ser produto de uma rede de emissoras como a NPR e a BBC, ou mesmo uma iniciativa de colaboradores por toda América Latina como o site Rádio Ambulante. É uma narrativa contemporânea que, ao abrir um leque de possibilidades, vai inaugurar também pequenos ou, quem sabe, grandes - como no caso da primeira série de Serial, um produto da norte-americana pública NPR - audiências a consumir culturalmente os conteúdos. O que, evidentemente, estabelece pela diversidade de narrativas, assuntos e formatos de peças sonoras, não apenas um conceito de ouvinte expandido, mas um campo de estudo sobre as modificações da audiência no trânsito do som como formato desde o rádio ao podcast. Um estudo de campo apurado poderia constituir perfis de consumidores do podcast do ponto de vista cultural, ou seja, como o consumo cultural deles demonstra impacto na valorização da cidadania, do meio ambiente, da política e da economia.

Este preâmbulo é necessário para sabermos em que terreno social estamos pisando para pensar o ouvinte expandido: um terreno do aprendizado pelo som, de formatos que convençam a audiência naquilo que ela busca. Mas com as vias digitais de produção e espalhamento de áudio, a possibilidade de diversidade de discursos é infinita. Pode-se produzir livremente e espalhar com o que tiver à mão como rede. De redes de rádio como $B B C, N P R, C B S$, RAI e Rádio France a um quarto de adolescente de Uberaba, todos podem produzir um podcast $\mathrm{e}$ distribuí-lo no sistema aberto da internet. Esse é o princípio que se estabelece e, com ele, também uma circunstância de poder de diversidade na questão da produção. Esta é a resposta para um ouvinte expandido, também ele espalhado por muitos grupos, microuniversos de ouvintes.

\section{O ouvinte expandido}

Aquela situação no começo dos anos 1930, em que Benjamin, Arnheim e Brecht tentavam demonstrar o quanto o rádio podia ser interativo e não era, consagra-se parcialmente em nossos tempos, de uma forma que poderia deixálos ligeiramente satisfeitos. No ambiente atual, a tecnologia digital, com seus 
elementos que transitam no rádio, é melhor difundida hoje entre o público, como softwares de gravação e edição, aplicativos e interfaces de redes sociais que proporcionam comunicação direta com o apresentador da emissora. Todos podemos manipular essa tecnologia, ao ponto de não só participar da programação mais ativamente do que poderia o passivo ouvinte de 88 anos atrás, mas também criar um simulacro de emissora ou uma web rádio completa, um endereço de internet com programas, reportagens, uma série de podcasts em forma de reportagens ou programa de entrevistas, documentários, programas radiofônicos de diferentes gêneros, igualmente ao que fazem as emissoras de rádio que mantêm sua transmissão por ondas sonoras e por seus site na internet.

Uma das modificações provocadas pela intensidade da interatividade ouvinte/ internauta com as emissoras de rádio repousa sobre as ações dos jornalistas que trabalham nos setores de apuração, que podem ser chamadas de central informativa. Esse setor, que antes limitava sua busca de informações nos vários órgãos sociais, como polícia, bombeiros, controle de trânsito, transportes, setores políticos, empresariais, terceiro setor e se mantinha ligada como uma grande antena em todos os canais de televisão, emissoras de rádio e sites informativos, passam, com o desenvolvimento da vida digital, a expandir sua busca pelas redes sociais, tentando encontrar indicativos de novas pautas a serem realizadas pela equipe, em conversas dos perfis mais seguidos do Facebook, Twitter, Instagram e Snapchat, principalmente. Ao mesmo tempo, recebem da própria equipe que repercute o que vai ao ar as informações que ouvintes enviaram por WhatsApp ou outros softwares e que são potenciais para apuração e desenvolvimento de novas notícias.

Também os sites das emissoras e as páginas do Facebook que transmitem parcial ou integralmente, ao vivo, as programações, proporcionam uma interação ainda mais ampla do que a emissão tradicional pelo ar, uma vez que o usuário em interação pode dar opiniões, responder a pesquisas e criar mensagens a serem enviadas (HERREROS, 2008). Além disso, nos site surgem ou podem surgir cibergêneros (HERREROS, 2008), próprios da informação por áudio, modificados por força do encontro entre o rádio tradicional e a vida digital, gerando novas 
possibilidades. Exemplo: o gênero reportagem, que, na história do rádio antes da internet, era um segmento sonoro resultante do trabalho do repórter, contendo depoimentos de pessoas relacionadas com o fato em questão, mesclados com a fala do repórter e, eventualmente, som do local do acontecimento passa nesta era a ser algo a mais. Enquanto a emissora transmite o mesmo gênero descrito acima, no site, junto com a reportagem que foi ao ar pelas ondas hertzianas, pode-se acrescentar as entrevistas na íntegra e documentos completos para pesquisas mais amplas sobre o assunto tratado.

O ouvinte expandido que reivindico é a expressão de uma nova experiência, na qual ele passa a ser considerado um ser individual, destacado de uma massa que nos anos 1930 tinha como única ação reativa desligar o rádio quando não gostava de algo que ouvia, segundo Benjamin. Esse ouvinte expandido, nos dias de hoje, passa a ser um elo fundamental da complexa rede interligada de comunicação que parte do apresentador -uma emissora de rádio formal ou um podcast que ele tenha ouvido - e caminha por intrincadas malhas comunicacionais que se interligam, formando possíveis milhares de pequenos grupos - comunidades de ouvintes - no quais, a cada interação, o indivíduo sente-se parte do sistema de construção dos conteúdos transmitidos pelo rádio ou por um podcast. Essa experiência do ouvinte na interpelação do apresentador permite "acessar a emergência de novas características que ainda não se concretizaram em ideologias, convenções, normas, fórmulas e gêneros" (GOMES, 2011, p. 18) e proporciona descobrir, nesse processo, o que é novo, sendo capaz de aproximar-se tanto da experiência de Benjamin quanto da estrutura do sentir de Williams.

Por tudo isso, não cabe a esse ouvinte que lida com um novo rádio e com áudio por vias digitais um lugar que não seja ele também novo e diferente do que aquele que ocupou no rádio do século XX. Como demonstrado, o rádio atual, com suas possibilidades de produção, propostas de conteúdos e interações e suas imbricações com as vias digitais e outras plataformas, além da hertziana, é o rádio expandido, como conceituado por Kischinhevsky (2016). E a interação do ouvinte com o podcast - produto originário do rádio - também é expandida 
por natureza. Para interagir com esse novo rádio como instituição social, temos o participante da comunicação que era o ouvinte, mas que agora opina, informa, faz perguntas, estabelece pautas, transforma-se em fonte da informação, põe no ar sua voz - ainda que controlada pelo emissor em seu antigo papel - e transforma sua atitude social a partir da interação com redes de ouvintes, constituindo uma comunidade despida de territorialidade pela característica digital da comunicação. Permite também um padrão de organização que pode ser estudado como teoria da cultura, que está "perpassada por todas as práticas sociais e constitui a soma do inter-relacionamento das mesmas" (HALL, 2013, p. 149), sintetizada como estrutura do sentir. Desta forma, o ouvinte de áudio/rádio torna-se, além do "abastecedor" de Brecht, um ouvinte expandido.

\section{Referências}

ARNHEIM, R. O diferencial da cegueira. In: MEDITSCH, E. (org.). Teorias do rádio: textos e contextos. Florianópolis: Insular, 2005. v. 1, p. 61-98.

BARTHES, R. A escrita do acontecimento. In: MEDITSCH, E.; ZUCULOTO, V. (org.). Teorias do rádio: textos e contextos. Florianópolis: Insular, 2008. v. 2, p. 213-218.

BENJAMIN, W. Experiência e pobreza. In: BENJAMIN, W. Magia e técnica, arte e política: obras escolhidas. São Paulo: Brasiliense, 2014a. v. 1, p. 123-146.

BENJAMIN, W. Reflections on Radio. In: BENJAMIN, W. Radio Benjamin. Londres: Verso, 2014b. p. 363-364.

BRECHT, B. Teoria do rádio. In: MEDITSCH, E. (org.). Teorias do rádio: textos e contextos. Florianópolis: Insular, 2005. v. 1, p. 35-45. 
CARLÓN, M.; SCOLARI, C. A. (org.). El fin de los medios masivos: el debate continúa. Buenos Aires: La Crujía, 2014.

CASTELLS, M. A sociedade em rede. São Paulo: Editora Paz e Terra, 2006.

GOMES, I. M. Gêneros televisivos e modos de endereçamento no telejornalismo. Salvador: UFBA, 2011. Disponível em: https://bit.ly/2j2n826. Acesso em: 14 jul. 2018.

HALL, S. Da diáspora: identidades e mediações culturais. Belo Horizonte: Editora da UFMG, 2013.

HERREROS, M. C. La radio em Internet. Tucumán: La Crujía, 2008.

KISCHINHEVSKY, M. Rádio e mídias sonoras: mediações e interações radiofônicas em plataformas digitais de comunicação. Rio de Janeiro: Mauad, 2016.

LÉVY, P. As tecnologias da inteligência. São Paulo: Editora 34, 1993.

MARCONDES FILHO, C. O discurso sufocado. São Paulo: Loyola, 1982.

MARTÍN-BARBERO, J. América Latina e os anos recentes: um estudo de recepção em comunicação social. In: SOUSA, M. W. (org.). Sujeito, o lado oculto do receptor. São Paulo: Brasiliense, 1995. p. 39-68.

MARTÍN-BARBERO, J. Dos meios às mediações. Rio de Janeiro: Editora UFRJ, 2013.

MIÈGE, B. A sociedade tecida pela comunicação: técnicas da informação e da comunicação entre inovação e enraizamento social. São Paulo: Paulus, 2009. 
ORTRIWANO, G. S. A informação no rádio: os grupos de poder e a determinação dos conteúdos. São Paulo: Summus, 1985.

SALOMÃO, M. Jornalismo radiofônico e vinculação social. São Paulo: Annablume, 2003.

WILLIAMS, R. Marxismo y literatura. Barcelona: Ediciones 62, 1980.

WILLIAMS, R. Televisão: tecnologia e forma cultural. São Paulo: Boitempo, 2016.

WOLTON, D. Elogio do grande público: uma teoria crítica da televisão. São Paulo: Ática, 1996.

submetido em: 07 out. 2018 | aprovado em: 18 fev. 2019 